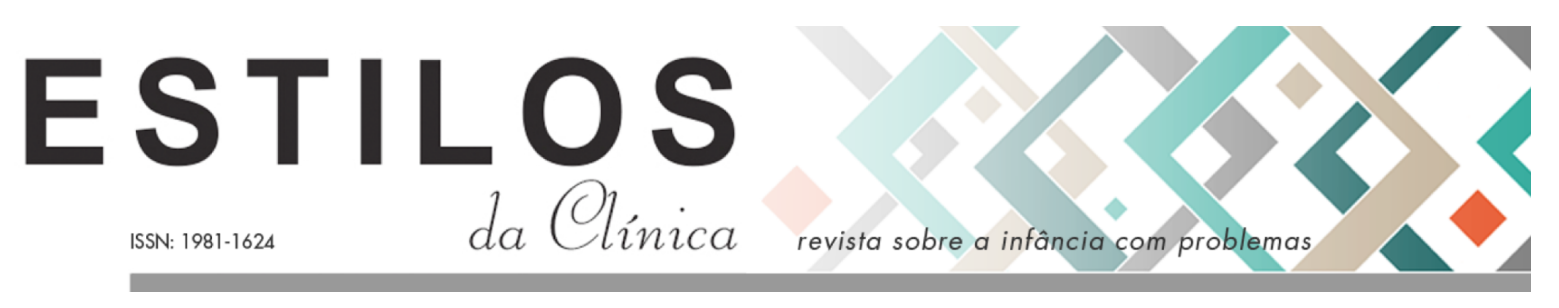

DOI: https://doi.org/10.11606/issn.1981-1624.v26i3 p520-535.

\title{
Artigo
}

\section{A culpa é sempre da mãe? Um olhar sobre a maternidade através da clínica com crianças}

\author{
Michelle Christof Gorin; Renata Machado de Mello; Terezinha Féres-Carneiro
}

Resumo. Este artigo pretende discutir questões relativas à maternidade a partir da prática clínica com crianças. Partimos das queixas relacionadas a alguns sintomas infantis que nos chegam para atendimento psicanalítico, para discutir o lugar da mãe na clínica de crianças. Levando em consideração que as mudanças sociohistóricas repercutem nas funções de cuidado dos filhos nas famílias, investigamos de que forma o aumento das possibilidades de destinos para as mulheres repercute nas experiências de maternidade nos dias de hoje. Utilizamos fragmentos de casos clínicos para ilustrar a discussão, evidenciando os desafios de envolver, sem culpabilizar, as mães nos atendimentos de criança.

Palavras chave: maternidade; culpa; clínica com crianças.

\section{¿La culpa siempre es de la madre? Una mirada hacia la maternidad a través de la clínica con niños}

Resumen. Este artículo pretende discutir cuestiones relativas a la maternidad a partir de la práctica clínica con niños. Partimos de quejas relacionadas a algunos síntomas infantiles que identificamos en el servicio psicoanalítico, para en seguida estudiar el lugar de la madre en la clínica con niños. Teniendo en cuenta que los cambios socioculturales influyen en las funciones de cuidado de los hijos en las familias, investigamos de qué forma el aumento de las posibilidades de destinos para las mujeres en la actualidad repercute en las experiencias de maternidad. Utilizamos fragmentos de casos clínicos para ilustrar la discusión, evidenciando los desafíos de involucrar a la madre en los servicios de niños sin culparla.

Palabras clave: maternidade; culpa; clínica con niños.

\footnotetext{
* Doutoranda em Psicologia Clínica pela Pontifícia Universidade Católica do Rio de Janeiro, Rio de Janeiro, RJ, Brasil. Email: migorin@gmail.com

** Pós-Doutora em Psicologia Clínica pela Pontifícia Universidade Católica do Rio de Janeiro, Rio de Janeiro, RJ, Brasil. Email: renatamello@gmail.com

*** Professora Titular do Departamento de Psicologia da Pontifícia Universidade Católica do Rio de Janeiro, Rio de Janeiro, RJ, Brasil. Email: teferca@puc-rio.br
} 


\title{
Is it always the mother to blame? A look at maternity through clinical practice with Children
}

\begin{abstract}
This article seeks to discuss maternity-related issues based on clinical practice with children. We started by gathering complaints related to certain infant symptoms that we identified at the psychoanalytical service and proceeded to study the place of the mother in clinical practice with children. Considering that sociocultural changes influence childcaring roles in families, we investigated how the current increase of possibilities for women affect maternity experiences. We used excerpts from clinical cases in order to illustrate the discussion, highlighting the challenges of involving the mother when servicing children without blaming her.
\end{abstract}

Keywords: maternity; guilt; clinical practice with children.

\section{La faute est-elle toujours de la mère? Un regard sur la maternité à travers la clinique de l'enfant}

Résumé. Cet article se propose de traiter de questions relatives à la maternité, à partir de la pratique clinique auprès d'enfants. Nous partons de plaintes liées à quelques symptômes infantiles qui nous parviennent en thérapie psychanalytique, pour interroger la place de la mère dans la clinique de l'enfant. Tout en prenant en considération que les changements socio-historiques traversent les fonctions de soin vis-à-vis des enfants dans les familles, nous cherchons à comprendre de quelle façon l'augmentation des possibilités de devenirs pour les femmes, se répercute sur les expériences de maternité de nos jours. Des fragments de cas cliniques sont utilisés pour illustrer la discussion et mettent en évidence les enjeux d'impliquer, sans culpabiliser, les mères dans l'accompagnement de leur enfant.

Mots-clés: maternité; culpabilité; clinique de l'enfant.

O que chamam de amor, nós chamamos de trabalho não remunerado. Silvia Federici

A culpa é sempre da mãe. Um clichê bastante utilizado, seja para atribuir responsabilidade à própria, enquanto figura materna, seja para criticar a psicanálise quando o faz, atribuindo à mãe toda a responsabilidade pelas questões dos filhos. Sabemos que ser mãe foi uma das respostas formuladas por Freud à intrigante pergunta sobre o que quer uma mulher. Porém, é indiscutível que a identidade da mulher vem se distanciando bastante da figura da mãe, dona de casa, boa esposa, a partir da entrada da mulher no mercado de trabalho, no final dos anos 1960; da crescente luta feminista por direitos iguais entre homens e mulheres; da aprovação da lei do divórcio há mais de quarenta anos; da obrigatoriedade da "guarda compartilhada" entre os pais a partir de 2014, e de sua consequente maior independência em termos gerais (Singly, 2012, Roudinesco, 2003). Além disso, as novas configurações familiares, o educar uma criança sozinha ou com outra mulher, as mulheres chefes de família, as novas 
imagens e símbolos da mulher, a reprodução assistida e a separação entre sexo e procriação também são evidências de abertura de novos campos e destinos para a mulher, questionando o emblemático princípio de que "mãe é sempre certa" (Marcos, 2017). Nesse contexto, cada vez mais, ter ou não ter filhos se torna uma decisão pessoal, de tal forma que os filhos deixaram de ser a finalidade ou a consequência inevitável do encontro amoroso (Singly, 2012). Dito de outro modo, o processo de "tornar-se mãe" apresenta-se, assim, muito mais dependente da história individual de cada mulher e de uma lógica do desejo, do que de um modelo de família nuclear tradicional (Zornig, 2012).

A opção pela maternidade, contudo, permanece ainda como um ideal significativo, mantido por muitas mulheres, e nos leva a pensar qual é o lugar do cuidado dos filhos na vida da mulher dos dias de hoje. Por outro lado, as crianças continuam demandando atenção, tempo, paciência, dedicação, como quem demanda uma "mãe dona de casa", isso sem falar no cuidado da casa. De acordo com os dados do IBGE (2016), as mulheres que têm ocupação com trabalhos fora de casa gastam em média cerca de $70 \%$ de horas a mais por semana com cuidados das pessoas à sua volta e com afazeres domésticos, em comparação com os homens que também trabalham. Nesse sentido, apesar de reconhecermos maior divisão de tarefas entre os gêneros, especialmente em determinados contextos socioculturais, a responsabilidade pelo cuidado com os filhos ainda recai muito sobre a mulher. $\mathrm{O}$ fato de a mulher ocupar outro lugar na sociedade não implica, necessariamente, em uma mudança correspondente no comportamento dos homens em relação à necessidade de assumir mais responsabilidades pelo cuidado dos filhos e administração da casa (Roudinesco, 2003; Riesco, 2018).

Nas redes sociais, por exemplo, podemos observar que há quem defenda que a qualidade do tempo com o filho é mais importante do que a quantidade, e que mães realizadas no trabalho inspiram seus filhos no que diz respeito à vida profissional. Há, também, aqueles que dizem que o importante é o tempo sim e que as crianças sentem falta de ser prioridade. Enquanto a demanda nos consultórios de psicanalistas de crianças aumenta com queixas de TDAH, TOD, depressão e inúmeras outras questões, nos perguntamos o quanto é difícil não cair na responsabilização, especialmente das mães, pelos problemas dos filhos. De certa forma, estamos acostumados a nos interrogar sobre o sentido do sintoma da criança, levando em consideração o discurso parental, a relação conjugal dos pais e o lugar da criança na família. Ao mesmo tempo, o manejo técnico relacionado aos pais na psicoterapia da criança se apresenta 
como um dos temas mais discutidos na área, evidenciando que o desafio de envolver a família no processo terapêutico, sem a culpabilização que despotencializa e afasta, não é de hoje.

A partir da nossa experiência clínica, podemos constatar a existência de muitas formas de ser mãe nos dias de hoje: mães muito idealizadas por ser a única referência estável para a criança; mães muito ocupadas com sua carreira profissional e pouco ocupadas com seus filhos, deles esquecidas; mães inteiramente ocupadas em ser mãe, o filho sendo tudo na vida delas. Tendo tais considerações como ponto de partida, pretendemos discutir questões referentes à maternidade e as repercussões nessa experiência a partir do aumento das possibilidades de destinos para as mulheres no dias de hoje. Partiremos da clínica com crianças, uma vez que, certamente, as mães/os pais que buscam atendimento para os filhos hoje não são os/as mesmas/mesmos do passado. Inicialmente, vamos examinar o lugar dos pais na psicanálise com crianças, levando em conta as transformações nos papéis sócio-históricos desempenhados por homens e mulheres. Em seguida, vamos discutir, a partir de diferentes enfoques teóricos, os destinos possíveis para a mulher e suas relações com a maternidade. Para ilustrar a discussão, vamos utilizar alguns fragmentos de casos clínicos nos quais as referidas questões se apresentam no atendimento de crianças e suas famílias.

\section{O lugar dos pais na clínica infantil}

A estreita relação entre o ambiente familiar e os processos de maturação infantil indica que a saúde emocional da criança envolve certas condições que podem expandir ou constranger o seu curso, ou seja, o cuidado parental pode favorecer o processo de diferenciação e subjetivação do filho ou dificultar tal processo.

A psicanálise de crianças surge com o trabalho de Freud sobre o pequeno Hans, relatado no artigo "Análise de uma fobia em um menino de cinco anos", publicado em 1909. Nessa primeira tentativa de tratar uma criança por meios analíticos, o pai da psicanálise conta com a colaboração do pai do menino. A análise de Hans se realiza em circunstâncias muito especiais. Nesta época, segundo Freud (1909/1996), conjugar na mesma pessoa a tarefa de analisar e de educar é o que permitiria as condições necessárias para a aplicação da psicanálise em uma criança. Segundo Abrão (2001), a análise de Hans é um marco bastante significativo, na medida em que permitiu compreender a importância da linguagem pré-verbal empregada pela criança. 
A partir de 1920, duas psicanalistas propõem a sistematização de um método de análise infantil com significativa consistência teórico-clínica: Anna Freud e Melanie Klein. Por um lado, Anna Freud (1927/1971) não pensa ser possível estabelecer com a criança uma relação puramente analítica, exercendo conjuntamente as funções de analisar e educar. Desse modo, coloca em primeiro plano o consciente e o ego da criança, atribuindo importância primordial à situação externa e ao nível da realidade. Klein (1927/1996), por outro lado, desenvolve um novo método de psicanálise infantil através do jogo, do brinquedo, do desenho, do recorte, procurando preservar todos os pressupostos fundamentais da psicanálise de adultos com o cuidado de adaptar a técnica analítica às mentes das crianças. Nesse sentido, trabalha com o inconsciente, concedendo uma importância quase que exclusiva aos processos internos e à fantasmática infantil.

Na França, no final dos anos 1930, surge o nome de Françoise Dolto. De acordo com Roudinesco (1988), Dolto lança as bases de um método psicanalítico para o tratamento de crianças centrado na escuta do inconsciente e inclui a posição parental no tratamento, apesar de não pensar o campo da análise infantil associado a medidas educativas. Dolto pertence à segunda geração de psicanalistas franceses e é reconhecida, por muitos autores, pelo seu prodigioso talento clínico. Na terceira geração surge outro nome de destaque dentro da psicanálise infantil: Maud Mannoni. A psicanalista francesa considera imprescindível escutar os pais durante o processo analítico das crianças, na medida em que eles estão implicados no sintoma do filho (Mannoni, 1979/2004). Isso, no entanto, não significa fazer um tratamento psicanalítico conjunto, mas permitir aos pais se situar em relação à sua própria história.

Se nos guiarmos pelos pensamentos de Anna Freud, que enfatiza a situação externa e a realidade, ao tratarmos a criança precisamos ter entrevistas com os pais para colher informações e, se necessário, orientá-los na educação do filho, intervindo na realidade da vida em comum. Se nos orientarmos pelos pressupostos de Klein, que confere uma importância quase que exclusiva aos processos internos, ao tratarmos a criança pela psicanálise devemos, se necessário, encaminhar os pais a outro analista para entrevistas de orientação e/ou análise individual. Se nos valermos dos pressupostos de Dolto e Mannoni, que incluem a posição parental no tratamento da criança, precisamos, muitas vezes, escutar os pais em entrevistas, não com o objetivo de orientá-los, mas de ajudá-los a redimensionar os problemas do filho, implicando-se. 
Nesse contexto, Aberastury (2012) propõe um clássico modelo de entrevista inicial com os pais, cujo objetivo é conversar sobre a criança (história e atualidade) e a relação dos pais com a criança (dinâmica familiar). São os dados obtidos durante o período inicial de avaliação da criança, com os relatos dos pais durante as primeiras entrevistas, que vão permitir compreender o funcionamento psíquico da criança e o sentido do seu sintoma. É importante acrescentar que, para a psicanalista, uma das funções dessa entrevista é justamente proporcionar certo alívio da angústia e da culpa dos pais despertadas pelo sintoma do filho.

Até os anos 1970, muitos analistas não concordavam em receber os pais, decidindo por encaminhá-los a outro analista. Tal posicionamento, contudo, foi sendo questionado ao longo das décadas por muitos analistas de crianças, especialmente no que se refere à primeira infância (Abrão, 2001). Atualmente, a grande maioria acredita ser importante acolher a transferência dos pais e oferecer uma escuta sensível para suas angústias e inquietações. Não é fácil lidar com as demandas que se sobrepõem no cotidiano da prática clínica com crianças, posto que lidamos com queixas dos pais, da escola, do pediatra, muitas vezes, com mais frequência do que com as queixas da própria criança (Mannoni, 1979/2004). Desse modo, estamos aqui interessados nas questões que remetem ao sofrimento da criança como sujeito, não se tratando, portanto, de adequar a criança às expectativas de terceiros.

Sem dúvida, consideramos que há um entrelaçamento entre o discurso parental e o sintoma da criança. Em uma primeira entrevista clínica, por exemplo, já podemos reconhecer a relação das forças inconscientes entre genitores, ascendentes e descendentes. Isso não significa, contudo, que os pais sejam culpados, mas que a criança se encontra imersa em um campo de afetação familiar. É importante precisar que compreendemos que a criança, em alguma medida, também é responsável pelo seu sintoma, o que nos autoriza a realizar um trabalho analítico com base em sua própria demanda (Zornig, 2008). Sem esta aposta, não seria possível escutar o sentido próprio do sintoma para a criança.

\section{O que quer uma mulher?!}

Simone de Beauvoir, no famoso livro "O segundo sexo" (1949/2016), dedica uma parte especial para criticar o olhar psicanalítico sobre a mulher. Para ela, Freud compreendeu o destino feminino a partir do homem, uma vez que, para fazê-lo, marcou diferenças em suas formulações sobre o modelo de constituição masculino posteriormente. Além disso, a autora 
insiste na questão da castração, entendendo que a psicanálise supõe que a mulher se sente mutilada, quando comparada ao homem, e que isso seria uma prevalência de uma compreensão sexual e patriarcal, desprezando outros aspectos importantes para um sistema teórico. Nesse sentido, as formulações psicanalíticas teriam um olhar sobre a mulher que não valoriza sua possibilidade de liberdade, mas sim de lugar de objeto do outro, do homem.

De fato, a discussão proposta por Freud em "Algumas consequências psíquicas da diferença anatômica entre os sexos" (1925/2018) parte da ideia da mulher como faltosa ou inferior. Ele aponta que o complexo de Édipo funciona como uma formação secundária para as meninas, uma vez que prevê o abandono da mãe como primeiro objeto em uma etapa anterior. O conhecimento do pênis levaria imediatamente ao reconhecimento do órgão masculino como superior ao seu, dando origem à inveja do pênis, e saber sobre a própria castração implicaria em uma ferida narcísica que, por sua vez, geraria um sentimento de inferioridade, primeiramente vivido como castigo e, depois, como condição universal das mulheres. Para Freud, é o afastamento da masculinidade, como repercussão do reconhecimento da diferença anatômica entre os sexos, que abre espaço para o desenvolvimento da feminilidade. Então, o desejo de possuir um pênis seria substituído pelo desejo de ter uma criança e, assim, o pai se tornaria objeto de desejo, enquanto a mãe, objeto de ciúmes.

Apesar de atribuir grande peso ao fator biológico, Freud também fez afirmações importantes que valorizam a construção social do feminino. No trabalho sobre "A feminilidade" (1933/2018), ele aponta que "nem sempre é fácil distinguir o que deve ser atribuído à função sexual e o que deve ser atribuído à educação social" (p. 338) e que devemos "atentar para que a influência das normas sociais não seja subestimada, normas que, de forma semelhante, forçam a mulher para situações passivas" (p. 318).

Nesse sentido, Kehl (2018) aponta como Freud e Breuer, apesar de não terem sido feministas, "se mostraram sensíveis em relação à pobreza das escolhas de destino permitidas às moças" (p. 354), podendo perceber como o casamento, conforme construído em sua época, não raro ajudava a diminuir a própria libido da mulher. Toda a descrição das diferenças do processo edípico e do abandono da mãe como primeiro objeto, preveem um trabalho maior para a menina e com desdobramentos importantes em seu psiquismo, mas, para além disso, Kehl (2018) aponta que os destinos para a libido da mulher, reservada principalmente ao amor conjugal e à maternidade na época de Freud, careciam de novas perspectivas. 
Diversos autores, como Badinter (1980), escreveram sobre outras perspectivas para a mulher, desconstruindo o ideal de maternidade. A autora resgata a valorização do bebê e da criança desde o século XVIII, exigindo provas de amor e sacrifícios da mãe em prol do filho, sendo qualquer coisa diferente disso capaz de desencadear culpa e reprovações dos outros. Apesar de se atribuir a responsabilidade da criação dos filhos em toda sua complexidade às mulheres, Badinter (1980) destaca que o amor materno não é inerente e inato, como muitas vezes se supõe, considerando então o instinto materno um mito que, na verdade, dependeria de cada mãe, de sua história e da cultura.

Mesmo quase quarenta anos após a publicação de "O mito do amor materno", ainda é necessário discutir o tema em sentidos parecidos. A socióloga israelense Orna Donath, realizou uma pesquisa intitulada "Mães arrependidas" (2017), com mulheres que descreveram abertamente suas experiências de maternidade como algo que não valeu a pena. De acordo com a autora, a discussão busca abrir espaço para a reflexão sobre a transição para a maternidade, a identidade feminina e, também, o que de fato mudou ou não no olhar do social sobre ser mãe.

De acordo com Donath (2017), o desejo de ser mãe ainda é visto como natural, inato, biológico, mantendo um ideal social que não abre verdadeiramente caminho para que as mulheres escolham se querem ou não ser mães. Uma das evidências desse pensamento é que, apesar do reconhecimento das dificuldades que a transição para a maternidade pode instigar, ou a ambivalência inerente a essa experiência, espera-se que as mães sempre consigam superar e se desenvolver emocionalmente, caminhando para uma experiência integradora de maternidade, com esperança de superarem suas dificuldades. A autora discute como isso não ocorre com diversas mulheres e que muitas mães se sentem presas à experiência subjetiva da maternidade, eliminando sua capacidade de se mover e sentir que são donas das próprias vidas, uma vez que suas consciências precisam estar tomadas pela maternidade. Esse cuidado com o outro funciona em um tempo diferente do relógio, sendo uma preocupação permanente, sem início e fim, exigindo disponibilidade constante.

Donath (2017) também indica que julgamentos sociais podem dificultar a experiência da maternidade, no que diz respeito à impossibilidade de assumir publicamente as frustrações geradas pela maternidade ou considerar o arrependimento por ter filhos como uma irresponsabilidade ou defeito moral. Discute, ainda, como homens continuam tendo mais autorização social para não serem responsáveis pela criação dos filhos, como se não fosse uma característica inata deles ter que cuidar dos filhos. Para a autora, essas mães fantasiam uma 
realidade diferente, em que os filhos não existem, não apenas de forma momentânea, de forma que o tornar-se mãe pode ser vivido como traumático por algumas mulheres.

Muitas mudanças ocorreram no ser mulher e muitas ainda estão em transição, mas fato é que a maternidade não é mais o único destino possível para a mulher. Na clínica com crianças, especialmente considerando famílias pertencentes às camadas médias da nossa população, percebemos mães ambivalentes em relação a essa questão. E se, por um lado, aspiram ser mães, por outro, têm dificuldade em conciliar essa vontade com os outros aspectos da sua vida.

Essas vivências ambivalentes, contraditórias e sofridas da maternidade desencadeiam um enorme sentimento de culpa, o que aparece, muitas vezes, de forma inconsciente, provocando diversos sintomas e oprimindo o Eu de várias maneiras. A culpa tem suas origens no que Freud postula como um conflito entre as exigências pulsionais e as civilizatórias, revelando uma luta irremediável entre diversos impulsos do sujeito e a vida em sociedade. Nesse contexto, o superego se apresenta como a instância interna que tenta regular e inibir diversos desejos, demandando do ego que o atenda, ao lado das exigências do Id e da realidade externa, gerando culpa por tudo que é diferente e não atende ao que exige. A partir da dependência infantil dos cuidados parentais, uma parte do ego se transforma nessa instância, carregada de influências externas oriundas dos pais e se enche de ideais a serem supostamente cumpridos. A dissolução do Complexo de Édipo deixa o superego como herdeiro e sua severidade depende não apenas da realidade, mas da intensidade em que as tentações do romance familiar precisaram ser afastadas. Vale ressaltar que o sentimento de culpa e as exigências superegóicas se dirigem não apenas às ações, mas também àquilo que existe apenas como pensamento ou fantasia. A indagação a respeito da culpa que as mães vivenciam no exercício de cuidado dos filhos tem também o intuito de lançar luz sobre as exigências superegóicas individuais e grupais (Freud, 1940).

Fragmentos clínicos podem ilustrar os desenvolvimentos teóricos que apresentamos, recortados a partir dos objetivos desse artigo. Maria, mãe de Bruno de 8 anos, relata que o filho é muito mimado, ainda fala com voz de bebê e está atrasado na alfabetização. A mãe conta com irritação que o filho demanda demais dela. Acorda à noite e ela precisa levantar para acalmálo. Bruno não faz as atividades da escola sozinho, portanto, Maria precisa ajudá-lo quando chega do trabalho. Leva-o para a natação, por exemplo, enquanto faz ginástica, mas gostaria de fazer mais ginástica. Bruno, por sua vez, gostaria da presença da mãe durante a aula. Maria conta que adorava seu tempo de casada sem filhos, podiam sair todos os dias sem maiores 
compromissos. Ter filhos não era um desejo, mas acredita que chega uma hora que é preciso tê-los.

Daniel, com 7 anos, filho de Carolina, tem crises de angústia, chora muito e ninguém consegue consolá-lo. Carolina o considera extremamente mimado, pois quer ficar na sua cama e pede ainda comida na boca. O que mais a irrita é a quantidade de perguntas que Daniel lhe faz sobre tudo, temendo que isso vire uma obsessão. O filho costuma interromper a mãe quando mexe no celular e não entende que, às vezes, é assunto de trabalho. É impossível ficar sem babá na opinião da mãe.

João, com 6 anos, é bastante agitado. Segundo sua mãe Isabela, ele dá grandes chiliques no shopping querendo presentes, além de querer ficar na cama dos pais. Isabela se queixa que precisa acordar à noite para dar atenção para o filho e que ele ocupa a televisão o tempo todo em casa, querendo ver desenhos de criança e não filmes para adultos, embora isso seja inteiramente condizente com a idade dele. A mãe fica chocada quando o filho se impressiona com falas simples, como, por exemplo, quando lhe disse para ficar perto dela, pois alguém poderia pegá-lo na rua. No mesmo dia, João teve um pesadelo que alguém havia lhe roubado para longe dos pais. Isabela reclama muito que chega do trabalho exausta e João quer brincar com ela, mas o seu desejo é apenas tomar banho e descansar.

\section{Discussão}

Os fragmentos clínicos foram destacados tendo como foco as queixas e as dificuldades maternas a respeito do exercício da maternidade, de forma que existem inúmeros outros aspectos conscientes e inconscientes que poderiam ser investigados para além desses, mas que se distanciam do objetivo desse trabalho. Todos são filhos únicos e, nos três casos, as mães trabalham fora de casa e os pais exercem somente em parte as responsabilidades pelo cuidado com a família. Não pretendemos discutir o caso de cada criança especificamente, muito teríamos a falar sobre elas. Mas, é importante afirmar que são crianças, em análise, agradáveis, afetivas, saudáveis, com sintomas que não inspiram grandes preocupações. As mães, porém, pouco dizem de favorável e prazeroso a respeito de seus filhos. Em diversas situações clínicas, percebemos que os filhos buscam estar mais perto das mães: Bruno monta repetidamente um berço para ele e pede que a analista faça carinho nele como uma mãe. Daniel desenrola todo um carretel de barbante e passa por debaixo da porta em direção à mãe que está na sala de 
espera. João conta baixinho no ouvido da analista que vai continuar fazendo besteira na escola para poder manter as sessões, pois quer continuar a brincar com a analista.

O ponto em comum entre as mães dessas crianças nos parece ser irritação ou cansaço em relação ao filho, como se os mesmos demandassem mais do que o esperado. Maria se queixa de ter que acordar no meio da noite, ceder dos seus programas, do cansaço de ter que ajudar com as tarefas do filho. Assim como Carolina, que se queixa de o filho ser mimado e de suas interrupções contínuas, precisando de ajuda para cuidar dele sempre. Por sua vez, Isabela se queixa de ter que abrir mão de coisas por conta do filho e de ter que brincar com ele após o trabalho. As três mães parecem considerar que a maternidade exige mais delas do que gostariam ou do que haviam imaginado. Os pais não estão no centro desse recorte de discussão, porém aparecem de forma lateral nos discursos das mães e comparecem pouco para participar do tratamento dos filhos.

Com efeito, as representações sobre o filho já existem no imaginário das mães e dos pais muito antes do seu nascimento, refletindo o lugar idealizado designado à criança pelo casal parental e repercutindo nas relações entre pais e filhos. Desse modo, a concepção de uma criança põe em movimento aspectos narcísicos de cada um dos pais, englobando sonhos, medos, lembranças da própria infância, modelos paternos e maternos, determinando a forma como cada um dos pais vai poder exercitar a parentalidade (Zornig, 2012). Em seu artigo "Sobre o narcisismo: uma introdução" (1914/2010), Freud ressalta a importância dos ideais parentais para a invenção da subjetividade por vir. Desse modo, Freud propõe que o amor parental nada mais é do que o retorno e a reprodução do narcisismo dos pais, que colocam o filho no lugar de "Sua Majestade, o Bebê". Assim, através da idealização da criança, procuram resgatar seu próprio narcisismo infantil perdido.

Sabemos que muitos pais buscam constantemente a adequação do filho a seus ideais, independentemente do seu modo de ser, o que pode prejudicar a constituição de um espaço de trocas genuinamente afetivas e a captação dos movimentos e necessidades próprios da criança. Nesse sentido, o bebê real decepciona, necessariamente, em alguma medida, com relação ao bebê imaginado (Solis-Ponton \& Lebovici, 2004). Contudo, renunciar a um ideal que valoriza a imagem do filho, também provoca dificuldades, na medida em que a criança precisa do olhar materno cheio de admiração e boas expectativas para se constituir. Nos casos ilustrados, então, questionamos se o filho ocuparia tal lugar majestoso para as mães, alvo de atribuições e 
predicados, ou se isso é colocado em xeque de certa maneira, ainda que não se trate de uma falta de investimento narcísico.

É importante acrescentar que os ideais das mães são também atravessados pelos ideais sociais vigentes na cultura. Desse modo, nos parece, também, importante colocar em questionamento a ênfase concedida às queixas maternas, na medida em que a felicidade e a satisfação pessoal vêm sendo apresentadas como imperativos nos dias de hoje (Singly, 2012). Nessa direção, a sociedade contemporânea dissemina imperativos de bem-estar, prazer e satisfação imediata dos desejos, na contramão do sacrifício e da dedicação aos filhos como o principal sentido da vida de tempos atrás.

Nesse sentido, abrir mão de atividades individuais pelos filhos já deve ter sido algo vivido com mais facilidade pelas mulheres, quando não havia muitas alternativas. Hoje, notamos que há um desejo maior para que os filhos sejam autônomos e independentes. Nesse sentido, tudo que apontamos anteriormente, sobre os destinos possíveis para a mulher, nos lembra sobre os desafios de conciliar a maternidade com todas as outras esferas que se abriram para a mulher em sua vida. Muita coisa mudou desde os anos 1970, quando a mulher se dedicava integralmente ao cuidado dos filhos. Porém, essa emancipação feminina tem repercussões nas formas de cuidado com as crianças, que continuam demandando, independentemente da época, muito tempo e dedicação.

Como psicanalistas de crianças, ficamos atentas ao sentido do sintoma, e nos chama atenção que grande parte das queixas se relaciona a comportamentos infantilizados das crianças. Interrogamos se é possível relacionar esses sintomas à questão da dificuldade de conciliação dos interesses das mães na vida atual. Mães e filhos parecem insatisfeitos, para além da parcialidade característica da satisfação dos desejos. Os filhos parecem não se contentar com alguma coisa e, sentindo falta, mantêm um comportamento que busca ganhar mais atenção, continuando bastante dependentes, enquanto a expectativa materna era justamente do contrário, de que ficassem mais independentes e autônomos. Não se trata de culpabilizar um ou outro, mas o fato de buscarem atendimento indica que há um descompasso no ambiente familiar e, talvez, reconhecer o desafio dessa demanda de dedicação seja importante. Nesse sentido, é importante pensar que, de acordo com Winnicott (1963/1983), a conquista da autonomia se faz, inicialmente, pela satisfação da dependência da criança em relação aos cuidados parentais.

De alguma forma, o risco é que a falta de reconhecimento, por parte das mães, de seu cansaço ou de sua indisponibilidade, e suas repercussões nos filhos fazem com que vejam os 
sintomas dos filhos como essencialmente deles e não se impliquem nisso. É tarefa do analista de crianças indicar isso para as mães, para que possam acomodar suas demandas e também as das crianças. Mas, também é tarefa do analista ajudar as crianças a descontruírem possíveis fantasias de culpa em relação ao desencontro da família, ajudá-las a lidar com a falta inerente a qualquer relação, e também permitir o contato com a própria agressividade. É necessário que a família se adapte à criança, uma vez que ela é quem tem necessidades direcionadas aos adultos de quem depende, até pela imaturidade característica do humano. Mas, também deve haver um empenho em acolher o peso que isso, muitas vezes, gera para as mães, o que vai ser determinado, sobremaneira, pela presença ou não do outro par parental, ou ainda pela existência de uma rede de apoio.

Devemos aqui lembrar a literatura ressaltada que valoriza a compreensão da maternidade como uma escolha, e não como uma capacidade inata; portanto, as queixas das mães devem ser valorizadas e não enxergadas como falhas essenciais. Na mesma linha, atribuir as dificuldades das crianças a problemas individuais e essenciais delas mesmas caminharia no mesmo sentido de culpabilização das crianças, gerando possíveis diagnósticos injustificados. Entendemos então que o primeiro passo consiste em reconhecer e acolher o sofrimento de mães e filhos, sem estabelecer inicialmente relações de causalidade que podem atribuir culpa, despotencializando ambos. Além disso, convocar o pai ou outras figuras da família e da rede de apoio é também tarefa importante nesse sentido.

Em segundo lugar, devemos valorizar os sintomas dos filhos no trabalho individual com eles e no diálogo com a mãe, mas também com o pai. Esse tipo de situação desafia a inclusão da família no processo analítico da criança, conforme já discutimos anteriormente. Consideramos importante que a mãe possa ter seu próprio espaço para pensar suas questões, mas a interlocução com o analista do filho é central no tratamento, assim como a inclusão do pai (ou de outros membros da família) na discussão. Afinal, a distribuição de tarefas dentro da família e o compartilhamento do cuidado, após a emancipação da mulher, deve ser prioridade, para que não se acentue a sobrecarga feminina ainda mais. Assim, o analista deve conhecer as diferentes formas de inclusão da figura do pai na psicoterapia de criança, ou ainda, de uma rede de apoio, especialmente em se tratando de uma família monoparental. Pois, seja como for, cabe aos adultos que assumiram o encargo das crianças o risco e a responsabilidade de educá-las (Kehl, 2003). 
Se, por um lado, a maternidade pode ser vivida como uma privação de outras possibilidades da vida, os filhos podem construir uma demanda sem limites, através de diversos sintomas. O sentimento de culpa e as exigências superegóicas são centrais nesse conflito irremediável entre exigências internas e externas, conscientes e inconscientes, arcaicas e atuais. Obter satisfação através da maternidade é necessário para que o encontro entre mãe e filho se dê de maneira satisfatória para ambos, mas isso com certeza exige certa desidealização da maternidade e do bebê, embora não uma desidealização radical, já que ambos na vida real e na prática cotidiana envolvem uma demanda mais complexa do que se pode fantasiar. A ambivalência das mães é um tema central nessa problemática, devendo-se, portanto, tolerar a coexistência desses diversos aspectos no encontro entre mãe e filho que satisfazem e também desafiam a mulher. Nesse contexto, nos parece importante resgatar um prazer específico do encontro, nos servindo das postulações de Roussillon (2010) a respeito do compartilhamento de prazer capaz de sustentar o vínculo entre a mãe e o filho e a relação de dependência que se instaura.

\section{Considerações finais}

A discussão teórica apresentada indica a complexidade envolvida no exercício da maternidade nos tempos de hoje, em que há mais possibilidades de destinos para as mulheres. Abdicar de aspectos da vida individual, conquistas realizadas após a emancipação feminina, evidencia a dificuldade de conciliar os interesses da mulher e a maternidade. Simultaneamente, os filhos continuam demandando dedicação, cuidado, responsabilidade e suas queixas não podem ser, portanto, encaradas apenas como sintomas patológicos, mas pensadas em função do contexto relacional sociohistórico.

É necessário que os profissionais que atendem crianças estejam atentos à ambivalência intrínseca à experiência de cuidados dos filhos, que exige o acolhimento do peso do acúmulo de funções que ainda recai sobre a mulher, bem como das dificuldades da escolha em ser mãe, que não utiliza capacidades inatas e/ou instintivas, e desperta sentimento de culpa intenso. A não culpabilização deve, assim, ser um objetivo do trabalho analítico, bem como o envolvimento do pai (ou do outro par conjugal), de outros cuidadores e de toda uma rede de apoio. 
Consideramos que encontrar certa experiência de prazer na maternidade se mostra essencial para um bom encontro entre mãe e filho, bem como o investimento narcísico nos filhos e a revivescência do narcisismo materno. Por mais escolhas que a mulher tenha na contemporaneidade, a maternidade exige, de forma incontornável, sua implicação nos processos de desenvolvimento dos filhos. Conciliar todos os destinos possíveis de uma mulher envolve escolhas individuais e coletivas e a invenção de novas articulações para o exercício da maternidade.

\section{Referências}

Aberastury, A. (2012). Psicanálise da criança: teoria e técnica. Porto Alegre, RS: Artes Médicas.

Abrão, J. L. F. (2001). A história da psicanálise de crianças no Brasil. São Paulo, SP: Escuta.

Badinter, E. (1980). O mito do amor materno. Rio de Janeiro, RJ: Nova Fronteira.

Beauvoir, S. (2016). O segundo sexo. Rio de Janeiro, RJ: Nova Fronteira. (Trabalho original publicado em 1949).

Donath, O. (2017). Mães arrependidas. Rio de Janeiro, RJ: Civilização Brasileira.

Freud, A. (1971). O tratamento psicanalítico com crianças. Rio de Janeiro, RJ: Imago. (Trabalho original publicado em 1927).

Freud. S. (2010). Sobre o narcisismo: uma introdução. In S. Freud, Introdução ao narcisismo, ensaios de metapsicologia e outros textos (1914-1916) (Obras completas, P. C. Souza, trad., Vol. 12, pp. 13-50). Rio de Janeiro, RJ: Companhia das Letras. (Trabalho original publicado em 1914).

Freud, S. (2018a). Algumas consequências psíquicas da distinção anatômica entre os sexos. In S. Freud, Amor, sexualidade e feminilidade: Obras incompletas (pp. 259-276). Belo Horizonte: Autêntica. (Trabalho original publicado em 1925).

Freud, S. (2018b). A feminilidade. In S. Freud, Amor, sexualidade e feminilidade: Obras incompletas (pp. 313-348). Belo Horizonte, MG: Autêntica. (Trabalho original publicado em 1933).

Freud, S. (2018c). Compêndio de psicanálise. In S. Freud, Moisés e o monoteísmo, compêndio de psicanálise e outros textos (1937-1939) (Obras completas, P. C. Souza, trad., Vol. 19, pp 189-270). Rio de Janeiro, RJ: Companhia das Letras. (Trabalho original publicado em 1940).

IBGE (2016). https://www.ibge.gov.br/estatisticas/multidominio/genero/20163-estatisticas-degenero-indicadores-sociais-das-mulheres-no-brasil.html $?=\& \mathrm{t}=$ resultados $/$.

Kehl, M. R. (2003). Em defesa da família tentacular. In R. Pereira \& G. Groeninga, Direito de família e psicanálise: rumo a uma nova epistemologia (pp. 163-173). Rio de Janeiro, RJ: Imago. 
Kehl, M. R. (2018). Posfácio, Freud e as mulheres. In S. Freud, Amor, sexualidade e feminilidade: Obras incompletas (pp. 353-368). Belo Horizonte, MG: Autêntica.

Klein, M. (1996). Simpósio sobre análise de crianças. In M. Klein, Amor, culpa e reparação (pp. 165-196). Rio de Janeiro: Imago. (Trabalho original publicado em 1927).

Mannoni, M. (2004). A primeira entrevista em psicanálise. Rio de Janeiro: Elsevier. (Trabalho original publicado em 1979).

Marcos, C. M. (2017). O desejo de ter um filho e a mulher hoje. Trivium: Estudos Interdisciplinares, 9 (2), 246-256. doi : http://dx.doi.org/10.18379/2176-4891.2017v2p.246

Riesco, R. (2018). Igualdad de género y conciliación familiar: entrevista con Nuria Pumar Beltrán. Revista Estudos Feministas, 26(1). doi : http://dx.doi.org/10.1590/18069584.2018v26n144559

Roudinesco, E. (1988). História da psicanálise na França: a batalha dos cem anos. Rio de Janeiro: Zahar.

Roudinesco, E. (2003). A família em desordem. Rio de Janeiro: Zahar.

Roussillon, R. (2010). La dépendance primitive et l'homosexualité primaire « en double ». In B. Golse \& R. Roussillon, La naissance de l'objet (pp. 31-64). Paris: Presses Universitaires de France.

Singly, F. (2012). Sociologia da família contemporânea. São Paulo: Texto e Grafia.

Solis-Ponton, L. \& Lebovici, S. (2004). Diálogo Letícia Solis-Ponton e Serge Lebovici. In L. Solis-Ponton, Ser pai, ser mãe: parentalidade: um desafio para o terceiro milênio (pp. 2127). São Paulo: Casa do Psicólogo.

Zornig, S. (2008). A criança e o infantil em psicanálise. São Paulo: Escuta.

Zornig, S. (2012). Construção da parentalidade: da infância dos pais ao nascimento do filho. In C. Piccinini \& P. Alvarenga, Maternidade e paternidade: a parentalidade em diferentes contextos (pp. 17-35). São Paulo, SP: Casa do Psicólogo.

Winnicott, D. W. (1983). Da dependência à independência no desenvolvimento do indivíduo. In D. Winnicott, $O$ ambiente e os processos de maturação: estudos sobre a teoria do desenvolvimento emocional (pp. 79-87). Porto Alegre, RS: Artmed. (Trabalho original publicado em 1963).

Revisão gramatical: André Luiz Vale

E-mail: alavale88@gmail.com

Recebido em setembro de 2020 - Aceito em agosto de 2021. 